\title{
Know your enemy: recent records of potentially serious weeds in northern Australia, Papua New Guinea and Papua (Indonesia)
}

\author{
B.M. Waterhouse
}

\begin{abstract}
Waterhouse, B.M. (AQIS, PO Box 1054, Mareeba, Qld 4880, Australia) 2003. Know your enemy: recent records of potentially serious weeds in northern Australia, Papua New Guinea and Papua (Indonesia). Telopea 10(1): 477-485. Botanical collectors rarely specialise in introduced species. Consequently weeds are usually under-represented in herbaria, and comprehensive current checklists of local and regional weed floras are lacking. Potentially serious new weeds are often overlooked until they are widely naturalised and having a harmful impact on agricultural production or the environment. Weed surveys conducted under the auspices of the Northern Australia Quarantine Strategy (NAQS) have documented additions to the weed flora of northern Australia, Papua New Guinea (PNG), and the Province of Papua (Indonesia). New distribution records for the serious tropical weeds Chromolaena odorata (L.) R.M. King \& H. Rob. (Asteraceae), Mikania micrantha Kunth (Asteraceae), Cleome rutidosperma DC. (Capparaceae), Limnocharis flava (L.) Buchenau (Limnocharitaceae), Clidemia hirta (L.) D.Don (Melastomataceae) and Piper aduncum L. (Piperaceae), as well as two previously 'unknown' weeds Chromolaena squalida (DC.) R.M. King \& H. Rob. (Asteraceae) and Praxelis clematidea (Griseb.) R.M. King \& H.Rob. (Asteraceae) are discussed. Early detection and response to new invaders offers the best opportunity for cost-effective intervention. In PNG and Papua, detection of Chromolaena odorata facilitated expansion of an ACIAR-funded biological control program to include these regions. In north Queensland, infestations of Chromolaena odorata, M. micrantha, L. flava and Clidemia hirta are targets of eradication campaigns. Even though scarce resources and differing priorities prevent responses against every new invader, it is hoped that collection and dissemination of information on the spread of potentially serious weeds will have benefits for the entire region.
\end{abstract}

\section{Introduction}

Weeds are widely regarded as plants growing where they are not wanted and thus have nuisance value. This broad definition encompasses species that are either introduced or native to a region. For purposes of this paper, weeds are defined as introduced plant species that have become naturalised and invasive, with consequent potential for causing economic and environmental harm. Habitat degradation, loss of biodiversity, reduced water quality, animal and crop losses, increased production costs, increased incidence of herbicide resistance, contamination of produce and harmful effects on human and animal health are among the deleterious impacts of weeds.

Early recognition of new weeds presents the best opportunity for timely and costeffective intervention. Botanists should play an important role in drawing attention to new or recent naturalisations, but weeds are often under-represented in herbarium collections, and up-to-date checklists of local and regional weed floras are lacking. Serious 'new' weeds are often overlooked until they become conspicuous and widespread, by which time it is too late to prevent or mitigate their economic and environmental impacts; where early detection and appropriate response might have provided a different outcome. In northern Australia, botanists working under the auspices of the Northern Australia Quarantine Strategy (NAQS - a sub-program of 
the Australian Quarantine and Inspection Service), focus on collecting specimens of naturalised species in addition to native taxa. In this way NAQS surveys have provided a unique opportunity to consolidate knowledge of the weed flora of northern Australia, and to supplement and update information on the weed floras in neighbouring regions of PNG and Indonesia. Overseas surveys have also provided NAQS botanists with the opportunity to become familiar with weed species previously thought not to occur in Australia, thus increasing the likelihood of their detection in Australia.

\section{Methods}

\section{Target lists}

'Target lists' are used to help focus NAQS survey efforts and to promote awareness of potential threats (Mitchell 2001). These are lists of serious pests, diseases and weeds not yet recorded or of very limited extent and under official control in Australia, and known to occur in the adjacent region. Additional information and references for each target species accompany the lists. Regular revision and updating of the information is essential. The current NAQS weed target list (Waterhouse and Mitchell 1998) contains 41 species, several of which have been detected in northern Australia since completion of the list. During surveys attention is paid to any new weed irrespective of whether it is on the target list.

\section{Field surveys}

The primary objective of all NAQS survey activities is to detect new threats or incursions before they become well established, thus enabling implementation of preventative or remedial strategies at relatively low cost and with a high probability of success. In northern Australia, multi-disciplinary plant and animal health teams visit coastal and near-coastal settlements at a frequency determined by the perceived likelihood of quarantine incursions. This varies from twice yearly at some high risk Torres Strait islands to once every five years at low risk sites. Disturbed sites around habitation, road verges, cultivated plots, plantations, rubbish dumps, culverts and stream banks are searched thoroughly for weeds. Attention is paid to the vicinity of disembarkation points such as boat ramps and airstrips. Common and well-known weeds are recorded on checklists. Species that are poorly represented in collections, unknown weeds, or weeds thought to be recent arrivals are collected. Voucher specimens are submitted to state and national herbaria for identification or verification and permanent storage. To supplement survey activities, state and local government weeds officers and the general public are also encouraged to submit weed specimens for identification by the NAQS botanists.

Botanists or weed scientists from collaborating organisations in PNG and Indonesia participate in NAQS surveys in those countries. In PNG these survey activities are confined to the western border region of Western and Sandaun Provinces, and the coastal fringe adjacent to the Torres Strait islands. The same procedures are followed for documentation of the weed flora at each site. Local authorities and residents are asked which weeds have the greatest economic or ecological impact, and whether they have noticed any 'new' invaders. Voucher specimens are deposited in the PNG National Herbarium (Lae) or in Herbarium Bogoriense (Bogor). 


\section{Important records arising from NAQS surveys}

\section{Weeds with a 'history' elsewhere}

\section{Chromolaena odorata (L.) R.M. King \& H. Rob. (Asteraceae)}

Chromolaena odorata justifiably has a reputation as one of the world's worst tropical weeds (Holm et al. 1977). Originating from Central and South America, it is an aggressive invader of pastures and plantation crops, and is a major environmental weed, suppressing and smothering underlying vegetation. Seasonal dieback after flowering creates highly combustible fuel, promoting hot fires in vegetation that would otherwise rarely burn, including rainforests. Chromolaena odorata is one of the most damaging weed species throughout the Malesian region. In Australia, C. odorata would thrive along much of the coastal margin and adjacent hinterland from northwest Western Australia, through the Northern Territory and Queensland to northern New South Wales.

Prior to 1991, C. odorata was suspected to be present in Irian Jaya (now Papua) and known to be present in East New Britain (PNG) but had not yet been recorded on the PNG 'mainland'. Its presence near Jayapura and Merauke (Papua) was reported anecdotally in November 1991 and July 1993 respectively (J. Turner pers. comm.) following NAQS surveys for insect pests of crops in Papua. Following up the earlier report from the Jayapura district, a NAQS survey confirmed its presence just east of the PNG border at Wutung and Bewani near Vanimo (Sandaun Province) in June 1992. Voucher specimens were collected and submitted to LAE and BRI, and PNG and Australian authorities were notified. The record from Sandaun Province prompted botanists and weed scientists to search elsewhere, locating infestations near Lae and in other mainland provinces. The population of $C$. odorata has 'exploded' in the vicinity of Jayapura and Vanimo in recent years, probably influenced by deforestation and unusually dry spells (accompanied by fire) during El Nino weather cycles. This serious weed now threatens native vegetation, subsistence farming and other agricultural pursuits throughout the region.

The discovery of C. odorata in Papua and PNG led to the inclusion of both regions in a pre-existing biological control project funded by the Australian Centre for International Agricultural Research. Since 1997 two agents have been released: a leaffeeding Arctiid moth Pareuchaetes pseudoinsulata Rego Barros in PNG only; and a stemgalling tephritid fly Cecidochares (Procecidochares) connexa Macquart in PNG and Papua (Orapa, Bofeng \& Donnelly 2000, Wilson \& Widayanto 2000). To date, only the fly appears to have established readily. NAQS weed surveys in Papua since 1997 have recorded C. odorata in other regional centres including Timika, Nabire and Sorong. It is hoped that local personnel will redistribute populations of the stem-galling fly to these centres.

In July 1994, numerous small to extensive infestations of C. odorata were discovered in the vicinity of Bingil Bay and along the lower Tully River valley of north Queensland (Waterhouse 1994). Experience gained previously in PNG ensured instant recognition at this unexpected location. The discovery was reported to Australian authorities and an immediate search of the surrounding district determined that the infestations, while scattered over several hundred square kilometres, were confined to two adjacent catchments. Investigations and the discovery of two other related species from the same region (see below) led to the conclusion that $C$. odorata seeds were accidentally introduced in the late 1960s as a contaminant of pasture seed imported from Brazil. In view of the predicted broad distribution, ecological and economic impacts of C. odorata throughout tropical and sub-tropical Australia, a national consultative committee 
recommended that eradication should be attempted (Waterhouse 1994, 1996). The eradication program commenced in August 1994 and continues with annual reviews. The $C$. odorata population has been reduced substantially using herbicides, fire and mechanical control, although occasional small stands of mature plants continue to be discovered. The presence of viable seed in the soil is problematic and necessitates ongoing vigilance and treatment. To date, the eradication effort has been jointly funded by federal and state governments, including a proportion from those states likely to become infested in the absence of control. Large infestations of $C$. odorata were unexpectedly found on West and Home Islands of the Cocos Keeling group in 2000 (A. Mitchell pers. comm. 2000). It had been misidentified in 1987 and remained so for 13 years.

\section{Mikania micrantha Kunth (Asteraceae)}

Mikania micrantha is a rapidly growing perennial vine with small wind-borne seeds. It is native to Central and South America and widely naturalised in the Malesian region where it is regarded as a serious pest of plantations and pastures. Climbing to the canopy, dense infestations shade and inhibit the growth of native vegetation in forest gaps and margins. In Australia its potential distribution includes the more humid coastal regions of the Northern Territory, much of eastern Queensland and extends into northeastern New South Wales. In the weeds literature (eg. Holm et al. 1977), Mikania micrantha has been confused with the related species Mikania cordata (Burm.f.) B.L. Rob., which is native in South-East Asia and New Guinea. Although the latter species is also weedy, it has probably been displaced across parts of its range in Indonesia by the more aggressive M. micrantha (Soekisman Tjitrosemito pers. comm. 1997).

On the basis of specimens lodged at LAE, Henty and Pritchard (1988) noted records of Mikania micrantha from Bougainville, New Britain and the Central districts of PNG, suggesting a limited distribution in New Guinea. Recent NAQS surveys have recorded M. micrantha in the Merauke, Timika, Nabire and Sorong districts (Papua) and the Vanimo and Tabubil districts of PNG. This species is undoubtedly much more widespread in the region than our records suggest. Mikania micrantha is generally regarded as being a weed of the humid tropics. Discovery of a small but expanding infestation of $M$. micrantha in Merauke was unexpected because Merauke has a seasonal wet/dry climate with an average annual rainfall of only c. $1200 \mathrm{~mm}$, mostly falling between December and April. If this infestation persists and spreads, a much larger area of south-western PNG and northern Australia might also be vulnerable to invasion than is predicted by current eco-climatic models.

Although known to occur in Christmas Island, Indian Ocean (Du Puy et. al 1993) Mikania micrantha was first recorded in mainland Australia in June 1998, with the discovery of three small infestations at Bingil Bay, Mission Beach and Forrest Beach in north Queensland (Waterhouse 1999). In 2001, several additional infestations were discovered at Speewah and Ingham, also in north Queensland, but the total (known) infested area remains at less than 30 hectares. Several of the infestations abut rainforests of the Wet Tropics World Heritage Area. Although their origin is unclear, the infestations at Bingil Bay, Mission Beach and Forrest Beach were related. At Mission Beach and Forrest Beach plants had been intentionally cultivated for use as an herbal remedy for skin infections (C. Runow pers. comm. 1998). The origin of the Ingham infestation is unknown. Circumstantial evidence suggests a separate introduction to Speewah, possibly as a contaminant of imported palm seeds. All known $M$. micrantha infestations are now targets of an eradication campaign.

\section{Cleome rutidosperma DC. (Capparaceae)}

Cleome rutidosperma is a perennial herb native to Africa. It has recently become an important weed of crops and disturbed sites throughout South-East Asia, with 
particularly rapid expansion of its range in Indonesia (Soerjani et al. 1987). Elaiosomes on the seeds encourage dispersal by ants, and plants are often observed growing as epiphytes on cliff faces, stone walls and trees. Cleome rutidosperma was discovered for the first time on the New Guinea landmass during recent NAQS surveys in Papua, where it was recorded as a weed of annual crops (eg. peanuts), abandoned cultivation, roadsides and amenity areas in Jayapura, Merauke, Timika, Nabire and Sorong. Although not yet recorded from PNG, it will probably spread eastwards across the border as an accidental contaminant with cross-border traffic.

Several small populations of $C$. rutidosperma infesting an area of less than 10 hectares were discovered in Darwin, Northern Territory by NAQS botanist A. Mitchell in August 2000. In low numbers this species is relatively cryptic and difficult to locate amongst other herbaceous vegetation, so other infestations may remain undetected. Work has commenced to eradicate the infestations (A. Mitchell pers. comm 2000). Cleome rutidosperma has not yet been recorded elsewhere in mainland Australia, although it is reported as locally common in Christmas Island, Indian Ocean (Du Puy \& Telford 1993).

\section{Limnocharis flava (L.) Buchenau (Limnocharitaceae)}

Limnocharis flava is a clump-forming, perennial, aquatic herb native to Central and South America. Seeds and vegetative plantlets are dispersed by flowing water. Possessing attractive foliage and flowers it was probably introduced to the Malesian region as an ornamental species. It has subsequently naturalised and become a serious weed in padi rice, irrigation canals and wetlands in South-East Asia, where it is sometimes also cultivated as a green vegetable or pig fodder. Its potential distribution in Australia encompasses the humid tropical regions of the Northern Territory and Queensland.

Soerjani et al. (1987) noted that Limnocharis flava had not yet been reported from Irian Jaya (Papua). NAQS surveys in Papua in 1997 and 1999 recorded cultivated and naturalised populations of L. flava in the Jayapura, Merauke, Timika, Nabire and Sorong districts. It was probably intentionally introduced by Javanese transmigrants. Movement across the border into PNG as a source of food is inevitable, if it isn't there already. When allowed to grow unchecked, L. flava is a very invasive environmental weed of streams and wetlands. The RAMSAR-listed wetlands in Wasur National Park and the contiguous Tonda Conservation Area around the Bensbach River floodplain in PNG will be under direct threat of invasion if L. flava becomes widely established east of Merauke.

Limnocharis flava was recorded for the first time in Australia in June 2001, when several cultivated plants were discovered in an ornamental pond near Cairns, north Queensland. The source was traced to a wild population in a Cairns lake. Publicity about its potential weed status led to further detections in the Cairns and Townsville districts. The known infestations occupy an area of less than 3 hectares, but other plants are almost certainly lurking in suburban gardens and there may be undiscovered wild populations. Limnocharis flava has become the focus of an eradication campaign where plants are removed by hand and destroyed by deepburial. Infested sites will require regular ongoing inspection to locate and remove seedlings.

\section{Clidemia hirta (L.) D.Don (Melastomataceae)}

Clidemia hirta is a highly invasive shrub that is a pest of plantations and pastures and a serious environmental weed in humid tropical regions. Native to Central and South America it is widely naturalised in the Malesian region and Pacific islands. To date there have been no formal records of its occurrence in either Papua or mainland PNG, 
although Henty and Pritchard (1988) state that C. hirta had been reported recently from southern Bougainville. It is likely to have established elsewhere in New Guinea. Its potential distribution in Australia includes humid coastal sites in the Northern Territory and much of northeast Queensland.

Clidemia hirta was discovered for the first time in Australia in August 2001. A tiny infestation of at least several hundred plants was found at Julatten, north Queensland, while searching for Mikania micrantha (as follow-up to the recent discovery at Speewah). Avian and flood-borne dispersal of seeds was evident, with mature plants and seedlings scattered throughout a former palm nursery and along the banks and bed of an ephemeral stream running through the property. The source and duration of the infestation have not been determined. Every observed C. hirta plant was destroyed during a search of the area, but the characteristics of shade tolerance and birddispersed seed have increased the difficulty of detection of all plants. The infested area abuts extensive tracts of rugged forested land in the Wet Tropics World Heritage Area. Regular follow-up to locate and destroy seedlings, accompanied by an effective awareness campaign, will be essential for successful eradication.

Piper aduncum L. (Piperaceae)

Piper aduncum L. is a shrub or small tree, native to Central and South America but now naturalised and invasive in South-East Asia and some Pacific islands. Henty and Pritchard (1988) reported that it was already widespread at low elevations in New Guinea. Outside its native range it has been cultivated as an ornamental shrub, and the timber is reported to have been used to manufacture match-sticks in Papua (D. Suweny pers. comm. 2002). NAQS surveys have recorded P. aduncum near Jayapura, Nabire and Sorong in Papua, and the Vanimo, Tabubil and Lae districts of mainland PNG. We have also recorded it in the early stages of invasion in southern Bougainville. Anecdotal evidence suggests that it is much more widespread in both regions. Piper aduncum is a serious environmental weed. Mature plants often comprise multiple vertical stems arising from a horizontal stem growing across the surface of the ground. Dense infestations thus become impenetrable. Individual fruiting spikes contain huge numbers of tiny seeds that are dispersed by birds and mammals, and as contaminants of vehicles and logging equipment (Waterhouse \& Mitchell 1998). 'Wheatfield' regeneration of $P$. aduncum seedlings has been observed along roadsides, and in forest clearings in the Vanimo district. It rapidly invades disturbed sites and recently logged forests. At sites near Lae, P. aduncum has been reported to out-compete Chromolaena odorata (W. Orapa pers. comm. 2001).

Piper aduncum has not yet been recorded on the Australian continent, but is expected to be invasive in humid coastal regions of northern Australia. Recognition of its potential weed status in Australia has facilitated recent placement of $P$. aduncum on national and Queensland 'Prohibited plant' lists. However, like each of the other weeds discussed above, it may be already present and awaiting discovery. Du Puy (1993) recorded P. aduncum as a naturalised species on Christmas Island, Indian Ocean. A small population of about ten plants was still present there in 2000 (A. Mitchell pers. comm. 2001).

\section{Previously 'unknown' weeds}

\section{Chromolaena squalida (DC.) R.M. King \& H.Rob. (Asteraceae)}

State government officers responsible for the eradication of Chromolaena odorata from north Queensland, discovered a 0.5 hectare infestation of an unrecognised shrub, within the eradication zone. Leaf and flower morphology suggested that it might be a species of Chromolaena, but these plants were small (to $1.5 \mathrm{~m}$ tall), usually single- 
stemmed and generally did not appear to be invasive. Specimens could not be identified at Queensland Herbarium and were subsequently identified at the Smithsonian Institute as Chromolaena squalida, not previously recorded outside its native range in S. America (H. Robinson pers. comm. 2001). There is little doubt that C. squalida also arrived in north Queensland as a contaminant of pasture seeds imported from Brazil. Although it does not appear to be as serious a weed as its congener, it has been included in the C. odorata eradication campaign.

\section{Praxelis clematidea (Griseb.) R.M. King \& H.Rob. (Asteraceae)}

Praxelis clematidea is a relatively unknown weed, which poses an imminent threat of invasion to the Malesian region. It is an annual or short-lived perennial herb native to South America. Its native range overlaps with that of Chromolaena odorata and Chromolaena squalida in southern Brazil. It had not been recorded outside its native range until 1993/1994 when specimens from the Innisfail and Tully districts of north Queensland and Hong Kong were identifed almost simultaneously at KEW (N. Hind pers. comm.). Ironically, although $P$. clematidea had probably been present at both locations for at least 10 years, correct identification was delayed because it had been mistaken for the widespread and common species Ageratum conyzoides L. and Ageratum houstonianum Mill. (Waterhouse \& Corlett 1996, Waterhouse 2000). Veldkamp (1999) has published a description and ecological notes about $P$. clematidea (under the name Eupatorium catarium Veldk) to help draw attention to its imminent arrival in South-East Asia.

In the Hong Kong region, Praxelis clematidea has also been recorded in neighbouring southern China and Macau and in Taiwan. (J.F. Veldkamp pers. comm.). The origin of the Hong Kong and neighbouring infestations is unknown. The most plausible explanation for the introduction of P. clematidea to north Queensland is that it was also a contaminant of pasture seeds imported from Brazil, along with Chromolaena odorata and Chromolaena squalida. However, if this assumption is correct, P. clematidea has demonstrated greater dispersal and establishment capacity than $C$. odorata over a similar timeframe, and is now abundant in the region between Townsville and Mossman (latitude $16^{\circ}-19.5^{\circ} \mathrm{S}$ ), including the Atherton Tablelands. This area encompasses sites from near sea level to 800 metres elevation, and average annual rainfall $900-4000 \mathrm{~mm}$. Frost resistance has been demonstrated in Hong Kong and is suggested by occurrence of plants on higher parts of the Atherton Tableland. NAQS surveys have recently recorded small infestations at remote sites in Cape York Peninsula and on Thursday and Badu islands in Torres Strait. Praxelis clematidea is rapidly approaching New Guinea from the south!

In north Queensland, Praxelis clematidea is an abundant weed of roadsides, stream banks and pastures. It encroaches upon sugarcane plantations and other cultivated areas and is able to invade the understorey of relatively undisturbed woodlands. Seeds are readily spread as contaminants of vehicles, building and landscaping materials and garden mulch. Air-borne seed dispersal also seems to be effective over short distances.

In this case, Praxelis clematidea's lack of 'history' as a weed, and the fact that it was already widespread by the time it was correctly identified, means that it was not considered as a suitable candidate for eradication (or indeed any response). Landholders and concerned botanists are seeking implementation of local control measures to prevent or delay its further spread. It now threatens much of northern Australia (including more southerly parts of Queensland and northern New South Wales), New Guinea, South-East Asia and the Pacific Islands. 


\section{Discussion}

Early recognition and reporting of new weeds can lead to implementation of eradication or control programs at an early stage in the invasion process. By actively seeking, collecting and reporting weedy taxa, individual botanists can make a huge difference to the ecological and economic future of a region. For example, the early recognition and reporting of Chromolaena odorata in Queensland, probably represents a saving of millions of dollars annually (in the long term) and means that this species is unlikely to become a widespread and intractable pest in northern Australia (at least in the foreseeable future). Up-to-date inventories of the weed flora, validated by voucher specimens in major herbaria are essential for prioritising weed management activities in any region.

The relatively brief and infrequent NAQS surveys in Papua and PNG are unlikely to identify every new weed that has arrived, but hopefully will help draw attention to some of the major and emerging weed problems in the region.

\section{Acknowledgments}

Congratulations are due to the Australian Quarantine and Inspection Service for having the foresight to implement and continue to support 'early warning' surveys for weeds and other pests in northern Australia and adjacent regions. I would also like to thank our collaborating organisations in Papua and PNG who have facilitated surveys in those regions. Finally I would like to acknowledge the exceptional efforts of personnel in Queensland Natural Resources and Mines, who are responsible for a daunting list of eradication efforts. Collection and identification was the easiest part of the process!

\section{References}

Du Puy, D.J. (1993) Piperaceae. Flora of Australia Vol. 50: 73-76 (AGPS: Canberra).

Du Puy, D.J. and Telford (1993) Capparaceae. Flora of Australia Vol. 50: 167-170 (AGPS: Canberra). Du Puy, D.J., Telford, I.R.H. and Orchard, A.E. (1993) Asteraceae. Flora of Australia Vol. 50: 405-427 (AGPS: Canberra).

Henty, E.E. and Pritchard G.H. (1988) Weeds of Papua New Guinea and Their Control. Botany Bulletin No 7, 4th Edition. (Department of Forests, Division of Botany: Lae).

Holm, L.G., Plucknett, D.L., Pancho J.V. and Herberger J.P. (1977) The World's Worst Weeds. (University Press of Hawaii: Honolulu).

Mitchell, A.A. (2001) Plant plagues in Malesia. P. 63. 5th International Flora Malesiana Symposium, Sydney 2001, Program and Abstracts. (Royal Botanic Gardens: Sydney).

Orapa, W., Bofeng, I. and Donnelly, G. (2000) Management of Chromolaena odorata (L.) R. King and H. Robinson (Asteraceae) in Papua New Guinea: status of a biological control programme. P. 29 in Fifth International Workshop on Biological Control and Management of Chromolaena odorata, Program and Abstracts (Plant Protection Research Institute, Agricultural Research Council: Durban, South Africa).

Soerjani, M., Kostermans A.J.G.H. and Tjitrosoepomo G. (1987) Weeds of Rice in Indonesia. (Balai Pustaka: Jakarta).

Veldkamp, J.F. (1999) Eupatorium catarium, a new name for Eupatorium clematideum Griseb., non Sch.Bip. (Compositae), a South American species naturalised and spreading in SE Asia and Queensland, Australia. Gardens' Bulletin Singapore 51: 119-124.

Waterhouse, B.M. (1994) Discovery of Chromolaena odorata in northern Queensland, Australia. Chromolaena odorata Newsletter 9: 1-2.

Waterhouse, B.M. (1996) Chromolaena odorata in Australia: progress in eradication of an established infestation. Pp. 59-62 in Proceedings of the 4th International Workshop on Biological Control and Management of Chromolaena odorata. (University of Guam Agricultural Experiment Station: Guam). 
Waterhouse, B.M. (1999) Seek and ye shall find: new weed records from Irian Jaya, Papua New Guinea and northern Queensland. Pp. 105-111 in Weeds and Environmental Impact, Proceedings (II) of The 17th Asian-Pacific Weed Science Society Conference. (Organization of the Asian-Pacific Weed Science Society Conference: Bangkok).

Waterhouse, B.M. (2000) Weeds that are, or might be: a look at some "new" weed incursions in or near northern Australia. Pp. 180-185 in Proceedings of the $6^{\text {th }}$ Queensland Weed Symposium. (The Weed Society of Queensland Inc.).

Waterhouse, B.M. and Corlett, R.T. (1996). Overlooked but still invading: Praxelis clematidea the unknown weed. P. 408 in Abstr. Proceedings of the Eleventh Australian Weeds Conference. (Weed Science Society of Victoria).

Waterhouse, B.M. and Mitchell, A.A. (1998) Northern Australia Quarantine Strategy Weeds Target List. Ed. A.S. George. (AQIS Miscellaneous Publication No. 6/9: Canberra).

Wilson, C. and Widayanto, E. (2000) The biological control program against Chromolaena odorata in eastern Indonesia. P. 42 in Fifth International Workshop on Biological Control and Management of Chromolaena odorata. Program and Abstracts. (Plant Protection Research Institute, Agricultural Research Council: Durban, South Africa). 
